\title{
TEACHERS' REFLECTIONS ON THE VISUAL RESOURCES IN ENGLISH TEXTBOOKS FOR VIETNAMESE LOWER SECONDARY SCHOOLS
}

\author{
Thao Vu \\ (thao.hulis.vnu@gmail.com) \\ Haiduong College \\ Nguyen Thi Due, Hai Duong, Vietnam \\ Yusnita Febrianti \\ (yusnitafebrianti@gmail.com) \\ Universitas Negeri Malang (UM) \\ Jl. Semarang 5, Malang, East Java, Indonesia
}

\begin{abstract}
The prominent role of visual resources in language classrooms has long been advocated, as many argued that images could go beyond providing students with a visual background of the context or arousing motivation (Unsworth \& Ngo, 2014). This article explores the roles of the visual resources drawn from an English textbook series used in Vietnamese schools, and the teachers' reflections on their use of those visuals in practice. A qualitative approach was employed, involving in-depth interviews with teachers, along with an analysis of the visual resources using Kress and Van Leeuwen's $(1996,2006)$ framework of grammar of visual design. The findings show that the theoretical perspective resonates with the teachers' reflection in using visual resources in teaching and learning activities. The findings confirmed the importance of visuals in teachers' practices, but also highlighted the limitations of some images as useful resources for classroom learning. It was suggested that more attention be given to the multimodal nature of the text, and their significant contribution to meaningful learning activities. The selection of images in language textbooks should be more strategically and theoretically driven in order to prepare language-learning students with the ability to negotiate meanings across semiotic modes.
\end{abstract}

Keywords: visual resources, teachers' reflections, textbooks, meaning potential, framing

DOI: http://dx.doi.org/10.15639/teflinjournal.v29i2/266-292 
Communication and representation of meanings often involve more than the exchange of words alone. Other semiotic modes, including images, can actively play a significant part in the meaning-making process. As images are increasingly used not only in a complementary role to the verbal texts but also as an independent means of conveying meanings, it is no longer adequate to consider that literacy development simply involves the possessing of verbal information (Unsworth \& Chan, 2009). The fact that students these days encounter an expanding number of multimodal texts indicates that learning to construct meanings from the integration of images and language now needs to be considered as an important dimension of language competence (Unsworth \& Ngo, 2014). Therefore, it is essential that students learning a language should be equipped with the ability to negotiate meanings made by images and images in interaction with the language in texts.

Within the domain of second/foreign language learning, the significant role of visual resources in language classrooms has long been supported as language educators believe that visuals are beneficial to the learning of a language in a number of ways. Images can enrich learners' experience by supplying visual imagery, providing illustrations to the verbal texts, adding to understanding and pleasure, or serving as a specific reference point or stimulus (Omaggio, 1979; Wright, 1989). However, the roles of visuals can go beyond these functions, as Unsworth and Ngo (2014) argued that images can actively provoke language activities and language development through the meanings that they communicate. Therefore, it is necessary for teachers to recognize the rich potential that visual resources can contribute to the overall meaning of the texts and exploit them to facilitate students' language development. This is supported by Stokes (2002), who highlighted that in order for visual enhancements to be used most efficiently, teachers should possess skills that include the language of imagery as well as techniques of teaching visually. Given the need for this multimodal reality to be incorporated into learning experiences in language classrooms, textbooks should be designed to ensure that learners of English are learning to negotiate images as an integral aspect of functional English language competence.

Attempts to make English as a foreign language (EFL) textbooks a rich resource for classroom activities and more appealing to young learners by including attractively illustrated texts with colorful photographs and imaginative drawings, are not a new phenomenon in the tradition of textbook development. 
However, the use of visuals in education, although consistently shown to aid learning, must be carefully planned and strategically selected (Mueller, 1980; Stokes, 2002). We ask on what basis the selection of the visual aids for particular learning activities are made, and how these resources are then employed by teachers and students in the classrooms. This paper first gives a brief overview of the new series of EFL textbooks in Vietnam, developed within a national language project starting since 2008. It then provides an account of teachers' reflections about the roles of the visuals included in the learning activities in one volume of the textbook series, which is to be discussed together with an analysis of the meaning-making resource of images formulated in Reading Images: The Grammar of Visual Design by Kress and Van Leeuwen (1996, 2006).

The new EFL textbook series for Vietnamese lower secondary schools were developed as part of "Teaching and Learning Foreign Languages in the National Education System, Period 2008 - 2020" (hereafter referred to as Project 2020). Project 2020, considered as the most ambitious language initiative to date, was motivated by the pressing demand for English proficiency among Vietnamese citizens for personal and national development, along with the growing dissatisfaction with the poor quality of English language education in schools (Le, 2015; Nguyen, 2011).

Within this project, new English curricula and textbooks for the three levels of the basic schooling (i.e. primary, lower secondary and upper secondary) were developed, making English a compulsory subject from Grade 3 to Grade 12 , and instructional hours set to double as compared to the previous program. One of the guiding principles for developing the textbooks is to ensure that communicative language teaching and interactive learning are promoted (Hoang, 2015a). Accordingly, students are expected to develop their communicative competence through various communicative activities in meaningful contexts. The pilot curricula and textbooks have been tried out in a number of schools since 2010 at the primary level, and since 2012 at the lower secondary level. The new curriculum textbooks are claimed to contain "richly illustrated, cross-curricular and theme-based units, focusing on offering students motivation, memorable lessons, and a joyful learning experience" (Hoang et al., 2015a, p. iii).

According to a preliminary internal survey conducted by Hoang (2015b) in 92 primary schools across the country, the new curriculum textbooks for primary schools received positive feedbacks from the teachers concerning the 
quality, teachability and learnability. However, at the other two levels of schooling, there has been no research on the implementation of the trial, with no available information concerning the impact of this curriculum renewal in practice. Furthermore, although being richly illustrated with a number of photos and drawings selected and designed to be included in the textbooks, there is limited attention to the conceptualization and employment of the visual resource. Therefore, any investigation into the utilization of the visuals included in the textbooks is of practical significance, not only to increase the awareness among teachers concerning the visual competence, but also to enhance the quality of English language teaching and learning at schools.

The key framework of analyzing visual grammar is formulated by Kress and Van Leeuwen $(1996,2006)$ in Reading Images: The Grammar of Visual Design. This framework provides a fundamental outline to understand the structure of meanings in various forms of texts containing predominantly visual or a combination of visual and verbal resources. Inspired by Systemic Functional theory (e.g. Halliday \& Hasan, 1986; Halliday \& Matthiessen, 2004; Martin, 1992; Martin \& Rose, 2007), Kress and Van Leeuwen's notion of visual grammar reflects the realization of a simultaneous threefold purpose in every text: represented content of the world, the relationship of the communicating interactants, and the relevant organization in the communication method (Painter, Martin, \& Unsworth, 2013, pp. 6-7). Table 1 outlines the structure of the visual grammar framework to unfold across the three metafunctions: representational, interpersonal and compositional.

The framework has been adopted in education research involving the utilization of images as part of teaching and learning methodologies. Unsworth (2004), for example, analysed differences and similarities of the types of images in conventional books and computer-based texts. He found that although the types of images used in both formats were almost similar, the degree of complexity is higher in CD ROM formats. Unsworth and Ngo (2014) carried out an analysis of some images included in Vietnamese English textbooks for Year 10 students, commenting that some images included in the standard and advanced textbooks played a very limited role to the learning activities designed in the book, and called for more strategic selection and use of images. They also suggested that it was crucial for this multimodal reality to be incorporated into learning experiences in language classrooms by adopting textbook design aligned with the multimodal nature of English language learning. In addition, this framework is also used in the analysis of children's picture books (Painter, 
Martin \& Unsworth, 2013) in which the authors confirmed the complementary roles of visual images to the verbal languages in constructing the sequences of narratives in children's picture books.

Table 1. The System of Grammar of Visual Design (Kress \& Van Leeuwen, 1996)

\begin{tabular}{|c|c|}
\hline Metafunctions & Realisations in images \\
\hline $\begin{array}{l}\text { Representational (or ideational) } \\
\text { meanings } \\
\text { how images represent reality }\end{array}$ & $\begin{array}{l}\text { 1. Narrative: images that involves actions. } \\
\text { 2. Conceptual: images with classificatory } \\
\text { or analytical relationship between ele- } \\
\text { ments. } \\
\text { 3. Verbal: images with the use of speech } \\
\text { or thought bubbles. }\end{array}$ \\
\hline $\begin{array}{l}\text { The interpersonal (or interactive } \\
\text { meanings) } \\
\text { relationship between the participants } \\
\text { within the images and relationship be- } \\
\text { tween the image and the audience of } \\
\text { the text }\end{array}$ & $\begin{array}{l}\text { 1. Gaze: direct and indirect gaze of partic- } \\
\text { ipants in the image. } \\
\text { 2. Social distance: sizes of the images. } \\
\text { 3. Attitudes: involvement and detachment } \\
\text { based on horizontal and vertical per- } \\
\text { spectives. }\end{array}$ \\
\hline $\begin{array}{l}\text { Compositional meanings } \\
\text { the arrangement of images }\end{array}$ & $\begin{array}{l}\text { 1. Framing: weak and strong framing to } \\
\text { indicate connection or disconnection of } \\
\text { images. } \\
\text { 2. Positioning: left-right, top-bottom and } \\
\text { center-margin to indicate given and new } \\
\text { information respectively. }\end{array}$ \\
\hline
\end{tabular}

\section{METHOD}

This study is qualitative-descriptive in nature, with findings drawn from two sources of data: a content analysis of the textbook images, and in-depth interviews with teachers. The practicality of the image analysis lay in the elaboration of the meaning potential conceived in the visuals, and the roles they contribute to the learning activities in the textbooks. In-depth interviews with teachers offered an insightful understanding of teachers' reflections about their perception towards the roles of the images, as well as their preferred ways of visual exploitation in practice.

As the purpose of this study is to draw attention to the visual selection for a particular learning activity, an in-depth analysis of each individual image 
would be a pragmatic choice. Within the scope of this small-scale investigation, the images selected for analysis were drawn from Unit 7: Traffic in the new Tieng Anh 7, Volume 2 (Hoang et al., 2015b) for 7th graders. Unit 7 is also of representativeness as it was designed on the same format as other units included in the textbooks. These images were analysed using the Grammar of Visual Design by Kress and Van Leeuwen $(1996,2006)$ in terms of the three dimensions of meaning potential conceived by the images: the representational, interpersonal and compositional. The images used for illustration in this article have been reproduced with permission from the Vietnamese textbook publisher.

In-depth interviews with teachers aimed to gain insights into the reflections of those who have been working with the curriculum textbooks. Purposive sampling was used as a non-probability sampling strategy to recruit participants for interviews. Nine lower secondary school teachers of English (six females and three males) from nine lower secondary schools in a northern province of Vietnam agreed to engage in interviews. They are all senior teachers whose teaching experiences range from 12 to 21 years. All of them have at least two-year's experience in teaching the new curriculum. Details of the teacher participants were presented in Table 2.

Table 2. Details of the Teacher Participants

\begin{tabular}{lllcc}
\hline$\#$ & Name & School location & $\begin{array}{c}\text { Teaching } \\
\text { experience } \\
\text { (year) }\end{array}$ & $\begin{array}{c}\text { Time working with } \\
\text { the new curriculum } \\
\text { (year) }\end{array}$ \\
\hline 1 & Teacher G & Urban district & 12 & 2 \\
\hline 2 & Teacher H1 & Urban district & 15 & 3 \\
\hline 3 & Teacher H2 & Urban district & 18 & 4 \\
\hline 4 & Teacher H3 & Rural district & 14 & 3 \\
\hline 5 & Teacher H4 & Rural district & 15 & 2 \\
\hline 6 & Teacher H5 & Urban district & 12 & 3 \\
\hline 8 & Teacher K & Urban district & 21 & 3 \\
\hline 9 & Teacher N & Rural district & 15 & 4 \\
\hline
\end{tabular}

A semi-structured interview protocol was developed, in which most of the interview questions were open-ended in order to "allow the respondents opportunities to develop their responses in ways which the interviewer might not have foreseen" (Campbell, McNamara, \& Gilroy, 2004, p. 99). Interview ques- 
tions were piloted in advance in order to avoid any potentially ambiguous questions. As the researchers were based in South Australia and the participants were in Vietnam, the interviews were conducted via telephone. A total of 25 phone calls were made to the participants for time arrangements (12 calls), and interviews ( 23 calls). Before interviews, the participants were asked for their preference for the working language (i.e. English or Vietnamese), and all the teachers opted for Vietnamese. All of the interviews were audio recorded, then transcribed and translated into English for the purpose of data analysis.

The collected data were analyzed inductively into findings, which involved organization of information and categorization by means of coding. This process involved preparing and organizing the data, conducting a preliminary read-through of the interview texts, reducing the data into themes through a process of coding, and finally forming an interpretation from the data analysis (Creswell \& Clark, 2011, p. 179).

\section{FINDINGS AND DISCUSSION}

The findings of the study are informed by two important sources of data: interviews with the teachers and the analysis of selected images in the textbook. The results reveal that the theoretical perspective on the image roles in the textbook resonates with the teachers' perceptions of using visual resources designed in the selected unit of the book. The following sections present the results drawn from data analyses and the discussion of the findings.

\section{Teachers' Reflection on the Role of Visual Resources in Teaching and Learning Activities}

The results drawn from teachers' interviews show that all the teachers shared the same idea on the essential role of visual resources in their classrooms, and claimed that they used this resource as an integral part of their everyday teaching practice. When asked to clarify specific roles of images in English teaching and learning, the teachers said that images are rich resources that can be utilized for multiple purposes, i.e. introducing students to a new topic, invoking students' background knowledge of a topic, or providing contextual cues to a learning task. In many cases, visuals serve as illustrations of what is represented in the texts, or to make the book more colorful and inspiring. Some teachers noted that making use of visuals saved their lessons from being dull 
and boring as images can capture students' attention and arouse their interests. Therefore, visuals can contribute to higher learner engagement.

Acknowledging the significance of visuals in teaching and learning English, teacher $\mathrm{H} 1$ claimed that this kind of resources can motivate visual learners and emphasized the necessity of incorporating a wide range of images in the textbook:

It is very important to include visual resources in the textbook. Students do not like a book which is only full of words. In general, they enjoy the new book with a lot of beautiful pictures. (Teacher H1)

The teachers also supported the view that images are especially efficient in teaching vocabulary because this kind of resources can serve as visual cues to access meanings of the new words, and thus students can understand and remember the meaning of the words shortly.

Images are good illustrations for the introduction of new words. For example, the images of traffic signs in Unit 7 are very good. The students will remember the new words by remembering the images, and when they see the images, they can recall the words. (Teacher H4)

Regarding the sources of visuals used in a lesson, only Teacher H5, who developed her own power point lesson plans, preferred searching for the images which she believed interesting or relevant to her teaching objectives. The other eight teachers claimed that they always use the images available in the textbook as the main source of visuals. Teacher K, a senior teacher at a lower secondary in a rural district, stated that he always exploited the images included in the textbooks:

I always use the images printed in the textbook because I think that when the images are designed here, there must be some kinds of purpose, so I try to make use of them, for example, to introduce the context... I always ask my students to look at the picture, describe it or guess what is happening. (Teacher K)

Asking the students to look at an image and describe it by raising a number of questions like How many people in the picture, or What are they doing, etc. was a common way of exploiting the visuals. This highlights the fact that the teachers tended to focus primarily on representational meaning communicated in the images. Little attention was paid to interpersonal or compositional meanings to further understand the image, or to provoke further activities with 
it. To most teachers, visuals are restricted to complementary roles to the learning tasks. Therefore, when being asked about the role of images as an independent means of conveying meaning and their potentials for provoking further language activities beyond the learning tasks available in the textbook, all the teachers took time to think before their answers. Although some of them acknowledged this role of images, their use of images as an independent means for further language activities were rather limited.

I use pictures themselves to check the meaning of words, or use them to ask the students to make new sentences. (Teacher H2)

Some teachers automatically assumed that since the images were printed in the book, it meant that their duty was to use them without an idea of critically questioning the relevance of those visuals to the content or learning tasks. Teacher G, when being asked about the relevance of a particular image in relation to a learning task, felt quite confused as she never considered this issue before.

Actually I do not realize this matter. When I think an image is not relevant to a learning task, I just ignore it because I have a number of tasks in the book need to be covered before the bell rang. (Teacher G)

It is not surprising when the participants shared the same thoughts on the benefits of visuals to EFL teaching and learning as suggestions for using visual materials can be found in most approaches and methods to language education (Stokes, 2002). In the following section, teachers' perceptions of the role of the images included in the learning activities in the book will be discussed.

\section{Discussion of the Roles of the Visual Resources Included in the Textbook}

Overall, the arrangement of sections and sub-sections in the book aims to create an agreeable presentation of both layout and content. Page arrangement of information flow from left to right to represent the respective given to new information namely something presumably known by readers to newly presented information for readers to be particularly attentive to (Kress \& Van Leeuwen, 2006, pp. 180-181). Despite the obvious dominance of white as the background color, the pages are also highlighted by a combination of colors utilized to clarify or separate the sections or sub-sections. In this section, the analyzed images from the textbook are categorized into three groups namely useful, po- 
tentially useful and less useful images. This categorization was made based on the roles and functions of the images in the learning activities. These categories were described in the following section, supplemented with examples from the textbook and highlighted with the comments from teachers' experiences. Please note that the images presented in this section are arranged based on the page numbers they appear in the textbook.

\section{Useful Visual Resources}

These images function as useful resources for teaching and learning. Figure 1 includes mostly conceptual images (i.e. means of transport, traffic signs and flags), for vocabulary building and revision exercises on pages 7, 8 and 11 .
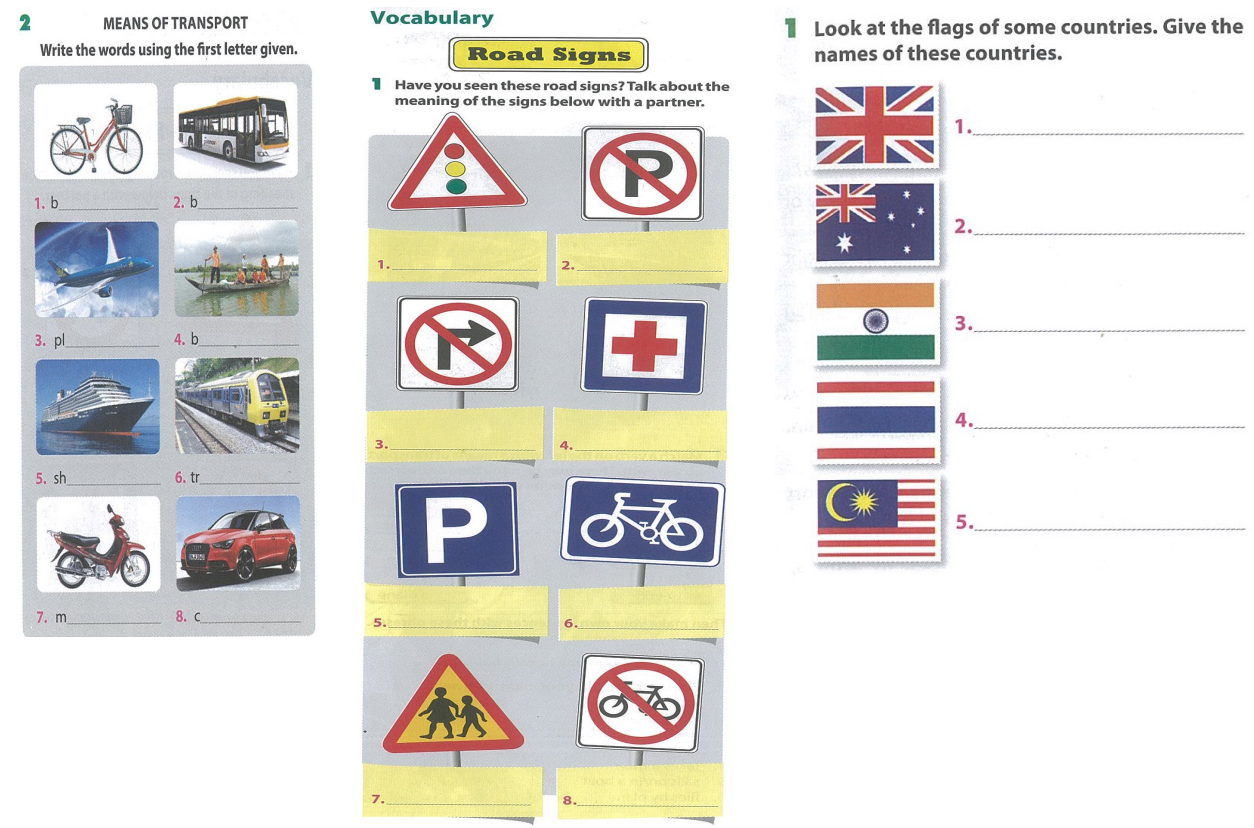

Figure 1: Conceptual Images for Vocabulary Building Activities (Hoang et al., 2015b, pp. 7, 8, 11)

In the exercises shown in Figure 1, instructions lead students to name the individually presented pictures which are indicated by frames with spaces pro- 
vided for answers. The images serve as visual cues through which students can identify the objects and then name them. For this type of exercises, representational meanings are more dominant and receive most focus. That explains the reason why all of the interviewed teachers shared the same view on the function of these images to the task requirement, and claimed that they are satisfied with this selection. Although all teachers did not wish to use these visuals for further activities after accomplishing the tasks required in the textbook, they have the potential of motivating further language activities. Teachers can go further by using these visuals as impetus for further discussion. For example, as shown in Exercise 2 on page 7 of the book, teachers can ask students to categorize the means of transports and motivate further discussion on a variety of issues relating to traffic, i.e. the potential for pollution and safety.

The multiple images in Figure 2 also received positive feedbacks from the teachers given their required roles in the tasks.

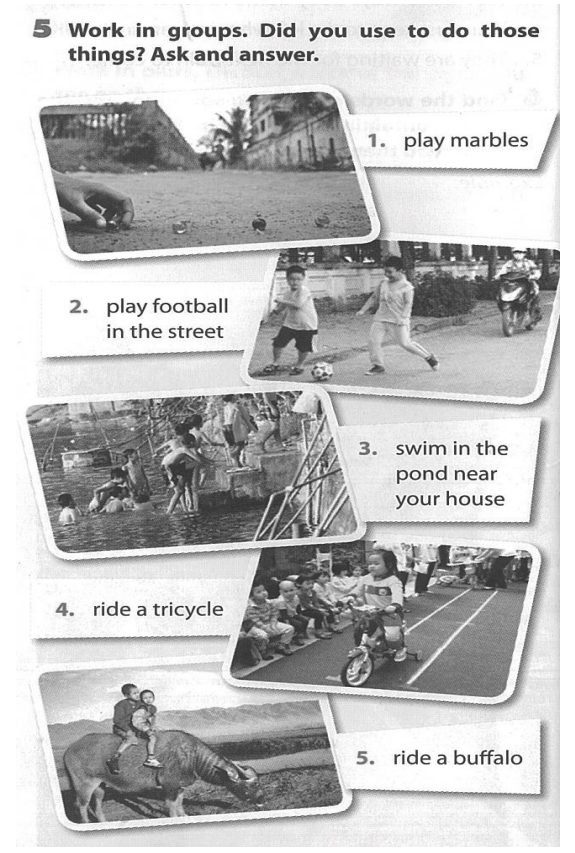

Figure 2: Narrative Images for Vocabulary Items that Represent Actions (Hoang et al., 2015b, p. 10) 
Exercise 5 on page 10 as shown in Figure 2 consists of five narrative images in which the vectors of the processes represent actions, i.e. holding marbles, chasing after the ball, or riding a bike. The images are strongly framed, and the verbal texts are in the form of labels presented in white rectangle boxes. The elements are placed in a non-parallel orientation, which helps to maximize space. These images depict authentic and common leisure activities of Vietnamese children, giving students a sense of familiarity, arousing their interest, and engaging their emotional response by recalling and sharing their past experiences with peers. Accordingly, they can provoke language use in relation to these kinds of childhood games. Although the images themselves already convey sufficient information about the represented games in the exercises, the inclusion of the verbal elements with the images allows multiplication of the meaning potentials (Royce, 1998). These verbal cues can support students with the key words needed to accomplish the task, especially for students of lower proficiency level.

Despite the issues of authenticity of the depicted bus stop which is clearly non-familiar to a Vietnamese setting, the visual shown in Figure 3 on page 9 bears meaning potential that will be useful to evoke further discussions.

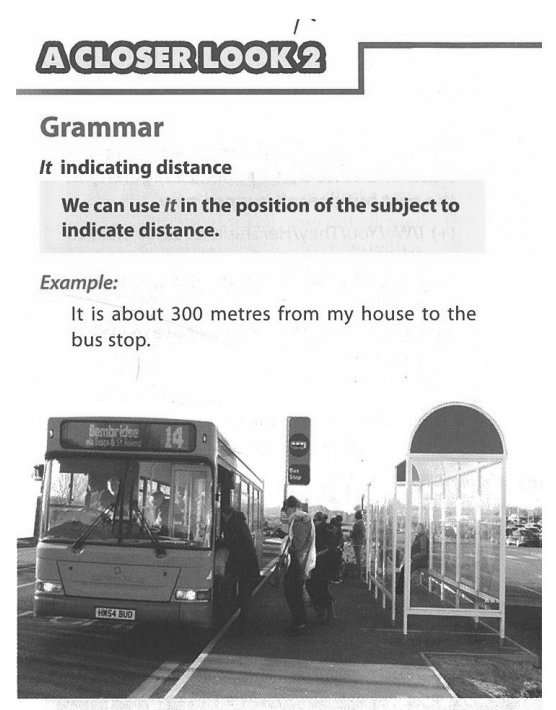

Figure 3: Useful Image from Non-authentic Vietnamese Real-life Context (Hoang et al., 2015b, p. 9) 
The movement of the participants in Figure 3 shows that they are getting on the bus, which does not serve as a logical illustration of the example 'It is about 300 metres from my house to the bus stop'. However, this image represents a comprehensible setting of a bus stop, and can be used independently as an impetus to discussion, i.e. comparison of typical Vietnamese bus stops with this foreign one, or having students talk about the distance from the bus stop to their school. Although there were two out of nine teachers who would prefer the choice of an authentic Vietnamese bus stop rather a foreign one, all acknowledged that they could still use this image as a resource for teaching.

\section{Potentially Useful Visual Resources}

This category provides an analysis of a number of images that play some role in the learning activities, but with limited functions. In these instances, the teachers noted that the images could be used as resources if improved with some changes. The visual resource in Figure 4 featured at the Getting Started section received a number of different comments from the teachers.

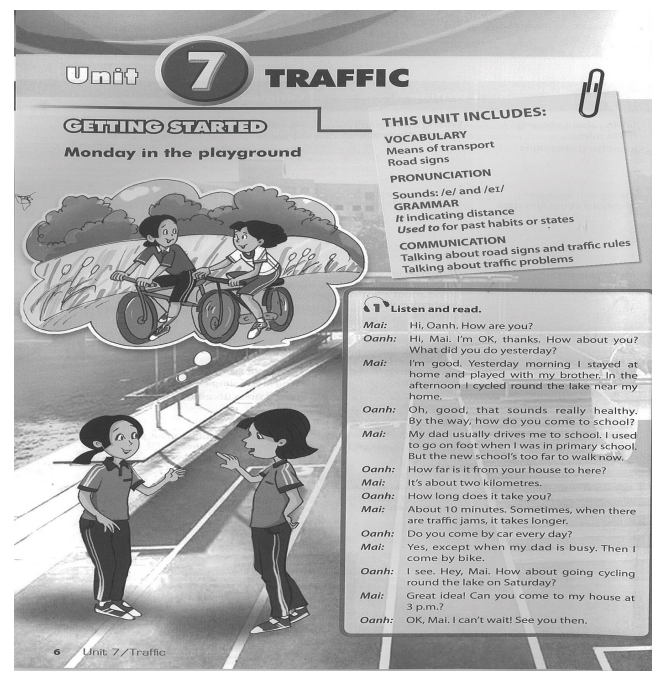

Figure 4: Images Supplementing the Information in a Conversation (Hoang et al., 2015b, p. 6) 
Representationally, Figure 4 is a narrative of two participants on an outdoor sporting track of a school. The vectors formed by the participant's gaze and body gestures indicates that they are engaging in a conversation. The text is arranged on the right side of the page, and transparently imposed on the image. By integrating the image with the text, we see that the participants' name in the image are Mai and Oanh. Mai and Oanh are characters depicted across the books, and by referring backwards and forwards to other units, we understand that the girl with tightened hair is Mai, and the other is Oanh. Above this image, framed within a thought bubble, is a narrative of two participants cycling in a setting which resembles a park or a countryside area. The movement direction of their legs and their gaze shows that they are cycling and talking at the same time. Interpersonally, there is no direct eye contact with the viewer; therefore, the viewers are not involved in the participants' world but are observing them. From a compositional perspective, the weak framing of the image implies a maximal integration to the text, and along with the strong blue frame of the text imposed on the image is to separate the text from the image.

There are a number of points in the teachers' interviews concerning this visual-verbal combination. Regarding the numbers of participants in this image, eight teachers said that there were two children named Mai and Oanh sharing their yesterday's activities and discussing a plan for cycling around the lake, while the other teacher believed that there are four different participants. This misinterpretation might result from the drawing qualities. Teacher K suggested that the characters need to be drawn in a way to make sure that teachers and students could recognize them as the same characters. Another feature that led to confusion for this teacher is the thought balloon. Speech and thought balloons do not refer to the same act as the former indicates a speech process whilst the latter refers to a thought process. In this case, the participants are actually speaking about rather than just thinking about the idea of their Saturday plan. Furthermore, the circumstance depicted in the balloon is also believed to be inefficient in illustrating the verbal text in that the two participants plan to cycle around the lake while the setting of this narrative depicts a park or a countryside area. In this aspect, the visual fails to support the verbal in the illustration.

Moreover, the teachers were not aware of the combination of drawings (participants) and picture (the setting of a school). Teacher G said that: 
I don't think this detail is important. I mean that small detail does not affect the content at all, so I do not pay attention to it. (Teacher G)

Teachers' not being aware of small details in the image reflects that fact that they did not really read the image intensively. This explains the fact that their exploitation of the image is restricted to asking students to observe the picture and to tell how many people there are, where they are and what they are doing, etc. as visual cues to lead to the dialog. They will then focus on the text. It seems that after the lead-in function, the visual has done its role.

Suggestions for more efficient design of this image as recommended by Teacher $\mathrm{H} 1$ and Teacher $\mathrm{K}$ is to improve the quality of drawing and to change the background to make it relevant to the text (i.e. cycling around the lake). Taking into account the copyright issue and the expense of setting up real photo shooting, Teacher $\mathrm{K}$ still proposed using pictures instead of drawings.

The image appearing on page 10 in the book, as shown in Figure 5, is also included in this category. The image depicts a conceptual representation of a street with a line of trees, a traffic sign on the right, and a traffic light on the left. This visual is arranged below a salient yellow box of grammatical rules of used to, and an exemplar.

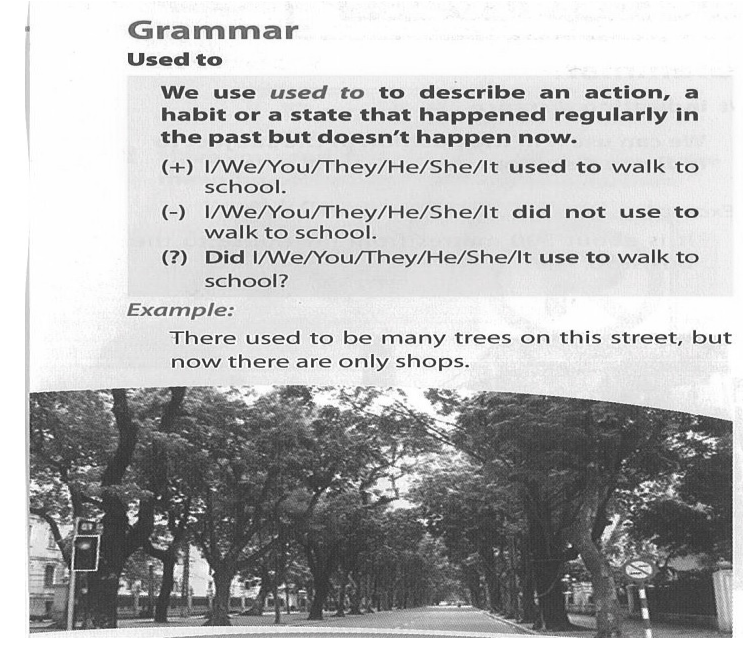

Figure 5: An Image with Less Relevance to the Sample Sentence (Hoang et al., 2015b, p. 10) 
Compositionally, the use of weak framing brings a maximal integration with the text. As regards to the role of this visual to the activity included in the book, 7 out of 9 teachers stated that the image is a perfect illustration for the first part of the provided example ("There used to be many trees on this street"). However, the second part of the example ("... but now there are only shops") remains unillustrated. The teachers found it difficult to explain the whole example sentence to show students how to use used to. The visual lacks connection to the verbal text, resulting in weakened functions of the visual in supporting the text. In this case, all the teachers suggested that it would be useful to include two images, one showing a street with trees, and the other showing a street with only shops.

The two images in Figure 6 below represent a long distance view of very busy roads. Students are asked to read the visuals to find answers to the questions in task 1. From the teachers' perspective, these pictures are relevant to the learning activities, but both need improvement.
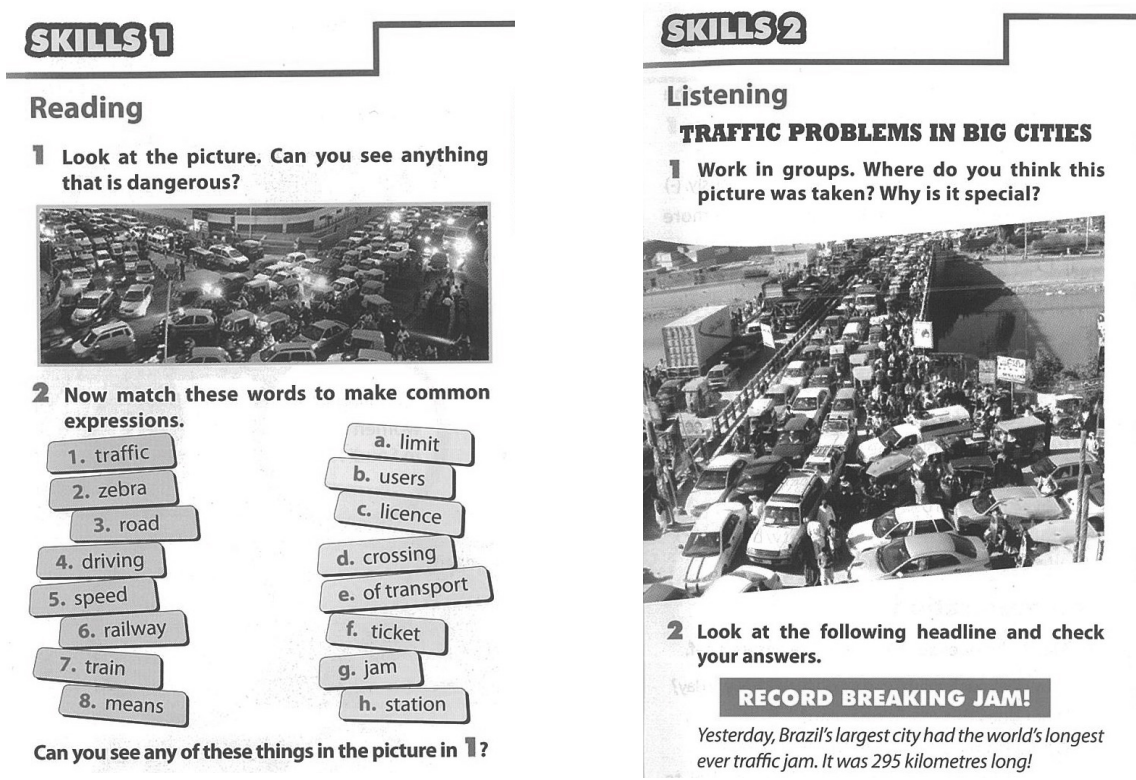

Figure 6: Complex Images within Small Frames (Hoang et al., 2015b, pp. 12-13) 
As perceived by the teachers, one of the problems with the picture in Skills 1 section is its size. Teacher $\mathrm{K}$ thought that this image is too small, which makes it difficult to observe and stay focused on its elements. Teacher H3 supported Teacher K's view in that due to its small size, it is impossible to see the details. She also said that she could not go further with this image because the image itself only reveals a street full of vehicles, which is very common in Vietnam cities where traffic jams during rush hour can be even worse. The traffic seems to go quite smoothly, and in most cases people get used to it and do not really see it as something dangerous. This problem can be explained by the fact that this image simply links to the topic as background, provides a form of peripheral, unspecified illustration and does not contribute directly to the potential of dangerous traffic situations to be discussed in the task requirement. Teacher H3 noted that when she asked her students to find something dangerous in this picture, her students responded there were too many cars and motorbikes on the street, and no further ideas were elicited from the students. This picture is also reused at the end of task 2, a vocabulary matching exercise. Students were asked to relate the matched expressions to the picture (Can you see any of these things in the picture in 1). For this activity, the picture becomes totally dysfunctional. The matched expressions (i.e. zebra crossing, driving licence, speed limit, railway station, etc.) do not directly indicate the dangerous traffic situations intended by task 1 , and bears no relation to the image. Therefore, Teacher $\mathrm{H} 3$ suggested that:

There should be another image to replace this one. In my opinion, an image in which there is someone who drives or rides on the wrong lane, or some pedestrians who do not walk on the right lane would be more suitable and students could discuss more. The input provided by this picture is not good. (Teacher H3)

The image in Skills 2 also performs a limited function in relation to the task requirement, which asks student to work in groups and discuss the location in which the image was taken and find the reasons why the image is special. While the focus of this section is on traffic problems in big cities, it can be predicted that the questions would lead students to think that the location of this image is in a big city. However, Teacher $\mathrm{H} 4$ argued the image included here seems not to represent traffic in a big city. Teacher $\mathrm{H} 3$ shared the same view and added that her students thought that this picture was taken in the suburbs of Ho Chi Minh City. Her students did not find the picture interesting because images of traffic jams or over-crowded roads are not a strange phenomenon to 
them. The main function of this task is as an activity to lead to the following listening task about a traffic jam in Brazil. For this purpose, an image that depicts a major traffic jam taken from a long-shot view to show the length of the jam would be more suitable and possibly provoke direct involvement with the listening task.

\section{Less Useful Visual Resources}

In some instances, the teachers noted that the images could not be used as useful resources. The image to be discussed is included in Figure 7 appearing on pages 8-9 in the book, which represents a two-way road with a number of cars.

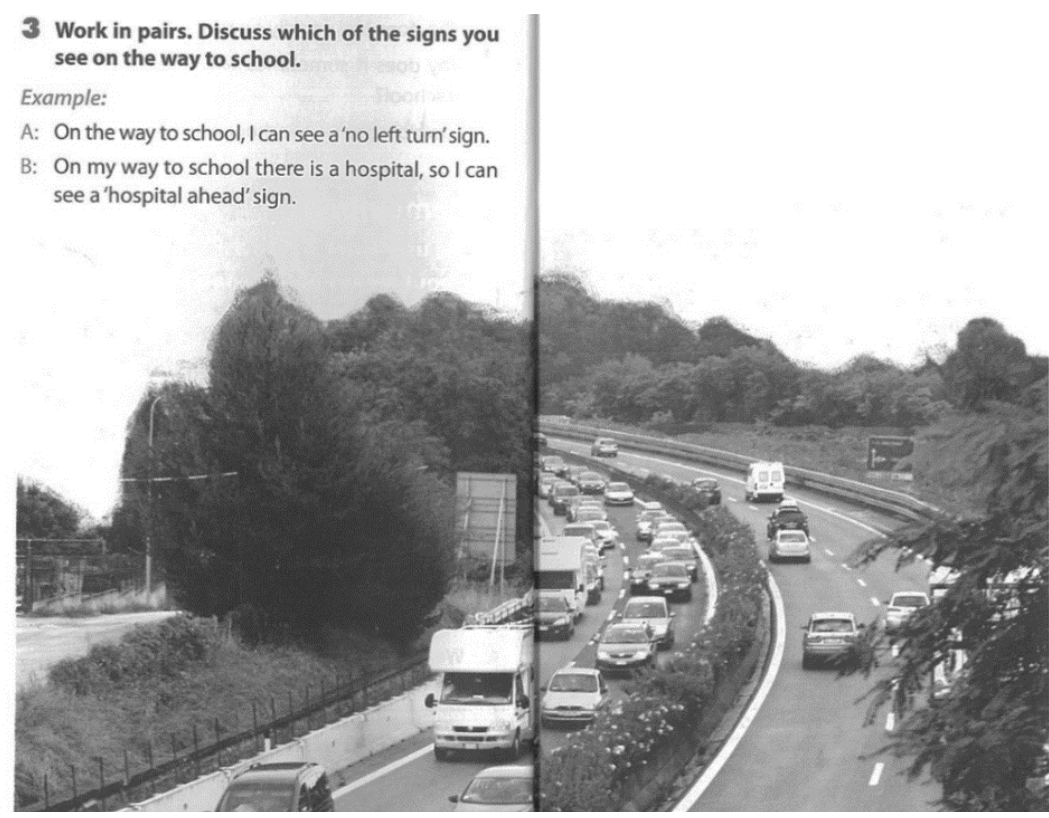

Figure 7: An Image that is Irrelevant to the Task Instruction (Hoang et al., 2015b, pp. 8-9)

As there are no houses along the road, it can be inferred that this road is not in the residential area. It may be connecting suburbs or in the countryside. 
Compositionally, weak framing allows maximal integration of the text on the left above the corner of the image. The prominent size of the image spread over two pages and its positioning bring a certain salience to this image in relation to other elements. However, the image is not linked to the verbal instruction. The task instructs students to "Discuss which of the signs you see on the way to school". However, there are no clear indications of any street signs represented in the image except an unreadable small blue sign on the right side of the picture, and another on the left side. The task targets discussion of traffic signs on the way to school, with an expectation that the image would include signs as visual cues for initial discussion or modeling. Since no clear traffic signs are depicted, this image fails to serve its primary function of supporting the task. The teachers made this point. For example, teacher N stated:

I couldn't use this picture. The task requirement is of talking about traffic sign on the way to school, but I can see no clear signs on the road depicted in the picture. The sign is shown from its back side which I can't tell what it is about. Therefore, I don't exploit this image. I just ask the student to imagine their way to school and remember whether there are any signs on the road and then talk about them. (Teacher N)

Others suggested it was a waste of space to use this large image with a negligible contribution. Suggestions for improvement included a selection of images that represented a residential street, perhaps with a roundabout with several traffic signs, or a country road with signs which would bring familiarity for the students and facilitate the discussion.

The image appearing on page 11 in the book shown in Figure 8 also lacks connection with the verbal element, making it dysfunctional for the learning activities included. The narrative image represents two children and an adult riding bikes. They all wear helmets and casual clothes which can be inferred that they are cycling for pleasure or physical exercise. There are no clues about the time and the place because the background is replaced by a semi-circle blue shape that plays no role in understanding the image. When relating this image to the learning activity, this image has no role in the listening task which asks students to listen and to reason why some countries drive on the left. The image bears no relation to left-right road rules, which makes it unrelated to the listening task. It is not surprising that the teachers found this image irrelevant in supporting the listening activity. Teacher $\mathrm{H} 4$ stated: 
This image doesn't show that these people are riding on the right or left side. The task requirement and the image don't match.

Teacher $\mathrm{N}$ thought that the selection of this image is "just to fill the space", resulting in a weakened function of the visual as a decoration. He suggested there would be a number of better choices of images; for example, an image that depicts a street in the UK where people are driving on the left, or simply a road with a "keep left" sign.

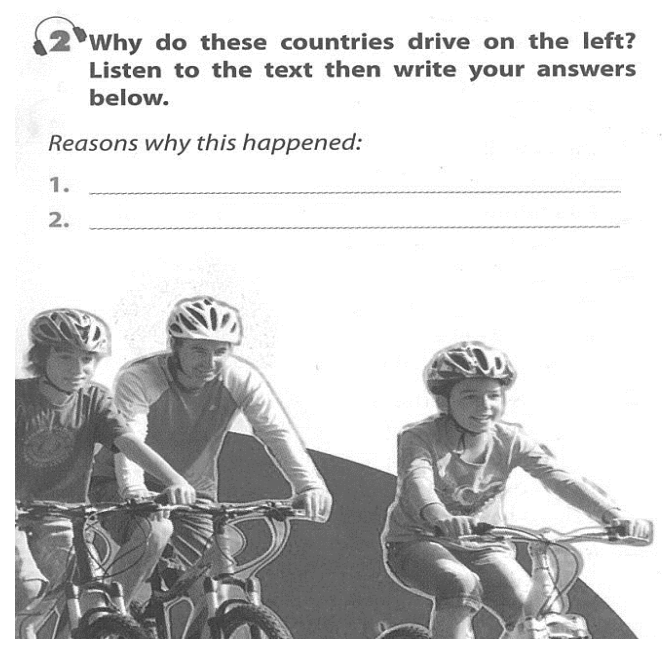

Figure 8: An Image that is Irrelevant to the Task Instruction (Hoang et al., 2015b, p. 11)

Another image that all the teachers found irrelevant to the learning task is the one appearing on page 13 of the book as presented in Figure 9. This image offers a long distance view of a busy city street in the evening with a lot of cars. The lights from the high-rise buildings along the street indicate that it is a big city. From a compositional perspective, the small size of the image makes it difficult for readers to see the details of the elements represented, and with the positioning of the picture in the right bottom corner of the page make it less prominent in relation to other images on the page. Teacher $\mathrm{H} 1$ stated: 
It is too small, and almost unusable because of its modest size. I don't get the authors' intention of selecting this image to be included in this section. I think this image is not necessary to this learning task. Actually, in this writing section, the students will produce their own output. This image becomes redundant here. (Teacher H1)

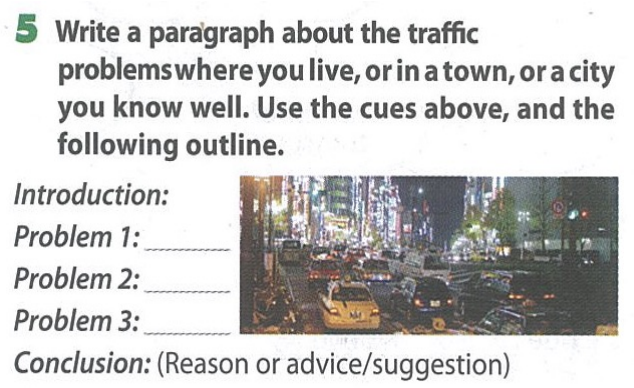

\section{Figure 9: An Image that is Irrelevant to the Task Instruction (Hoang et al., 2015b, p. 13)}

To accomplish the learning task shown in Figure 9, students are asked to use the cues in the previous task and the suggested writing plan. The image included has no role in supporting the writing process. Teacher $\mathrm{N}$ thought that the inclusion of this picture was only for the purpose of decoration, and thought that the designers wished to fill every space with pictures. Teacher G recommended that this picture should be omitted, giving the space for the students to use when they brainstormed ideas with their peers as part of the pre-writing stage.

The Project section is an innovative point of the new textbook series. It is designed to help students improve their ability to work individually and collaboratively in a team, which "extends their imaginations in a field related to the unit topic" (Hoang et al., 2015a, p. v). The section can be used as an extracurriculum activity for a group project, or as homework. This section is image dominated in comparison to written text. There were four tasks designed in a logical order: first students were asked to recall any traffic signs displayed around their schools, then made their own traffic signs, which they were going to show to the class, and finally displayed their self-made signs in appropriate places around the school. There is only one image representing a range of traf- 
fic signs in the middle of the page which actually plays some role in supporting the task requirements. Teacher $\mathrm{H} 3$ said that her students complained that these traffic signs are not Vietnamese ones; so are not ideal exemplars for the Vietnamese students as traffic rules in different countries may differ. She therefore preferred using real Vietnamese traffic signs which could be used to teach students traffic rules which she believed were essential life skills.

Figure 10 below simply provides peripheral illustrations and do not contribute to the learning activities.

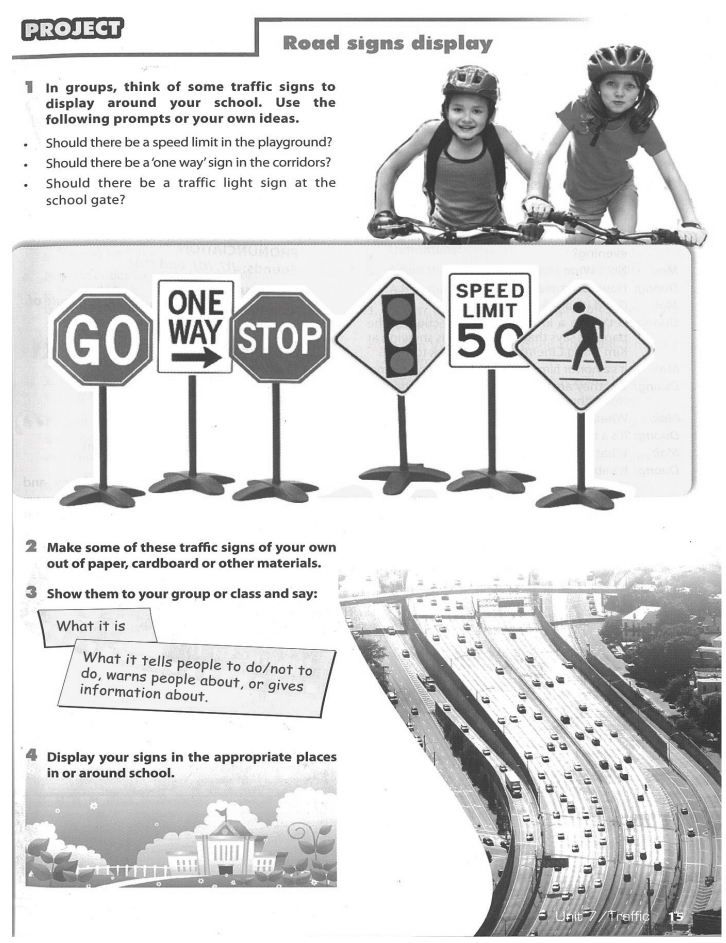

Figure 10: An Image that is Irrelevant to the Task Instruction (Hoang et al., 2015b, p. 15)

The image shown in Figure 10 which depicts two children riding their bikes taken from medium shot distance, both smiling with direct eye contact with readers works well in involving the viewer interpersonally. However, the back- 
ground setting is erased, which limits its interpretation. Furthermore, the inclusion of this image here has no role to any task requirements in this section. Similarly, the image of a multi-lane highway is not related to any tasks. The drawing included in task 4 is also dysfunctional and plays no role in supporting the task. While the task requires students to display the signs around their school, this drawing represents a building which does not look like a school.

Overall, the findings of this study are in support of the previous studies in regards of the significance of the roles of visual resources in supporting students' language competence. In light of Stokes' (2002) study that has pointed out the importance of equipping language teachers with capacity to use visual imagery in teaching and learning activities, this study approached the teachers as the forefront practitioners to reflect on their experiences of using visual resources in the textbooks for the teaching and learning activities. The study has also elaborated the theoretical justification of the sample images in the textbooks as meaningful visual resources which is in agreement to a study by Unsworth and Ngo (2014) that found the urgency of exploiting language-image interaction in textbooks as a source to support language competence development. While the study shows that the potential usefulness of some categories of visual resources in the textbooks are confirmed by the participating teachers, the findings also highlighted the presence of irrelevant images in the textbooks. Similar to the result of Unsworth and Ngo's (2014) study, the category of the less useful visual resources, unfortunately, is seen as a drawback of the textbook. They suggest that this type of images is clearly not designed to support the inclusion of images for language competence development. Hence, more strategic choices should be adopted to improve the overall design of the textbook.

\section{CONCLUSIONS}

This study has reported on information provided by a small number of teachers who are currently working with the new curriculum textbooks. The visual resources included in one unit of a textbook were categorized into three groups: useful images, potentially useful images and those that were not very useful. These categories were based in relation to the teachers' perceptions of the role of the images to the classroom teaching and learning, and on the theoretical perspective of visual images outlined in Kress and Van Leeuwen's $(1996,2006)$ framework of grammar of visual design. The findings show that 
the theoretical perspective resonates with teachers' perception in using visual resources in teaching and learning activities. Although the teachers acknowledged the essential roles that images can serve in their English classrooms, teachers' exploitation of images is still restricted as resources contributing to context introduction, interest engagement, illustration, or simply for decoration purposes. Teachers' main focus on the language element reflected the fact that they continued to assume that language alone fully represents the meanings encoded and communicated in the texts.

Due to the space constraints, this study only focused on the meaning potential of visual resources from one unit of the textbook. The findings were drawn from interviews and image analysis with no classroom observations, which would have significantly contributed to a deeper understanding of teachers' exploitation of images in practice. Notwithstanding the limitations of the investigation, we believe there are implications for the curriculum textbook image adjustment, teacher professional development and further research. Noting the limitations of some images, there is a need for more strategic selection of images, drawing on theoretical descriptions of the intersemiotic relationship between visual and verbal elements of texts. The incorporation of this multimodal reality into textbooks not only support students in deriving meanings from the images and image-language interaction in textbooks, but also prepare students for their critical negotiation with the range of contemporary multimodal texts that they encounter in everyday life. Visual resources in curriculum textbooks contain meaning potential that can be involved in thought-provoking activities, and to optimize their use, teachers should be equipped with some knowledge of how to analyze visual resources. Where applicable, the explicit teaching of the role of images in constructing meaning in texts could be integrated into classroom practice. Students then would be aware of the rich meaning potential that images can contribute to texts. Further studies on the roles of images included in the new Tieng Anh textbook series would be beneficial to the improvement of textbook design as a part of the textbook review analysis. 
290 TEFLIN Journal, Volume 29, Number 2, July 2018

\section{REFERENCES}

Campbell, A., Mc Namara, O., \& Gilroy, P. (2004). Practitioner research and professional development in education. London: SAGE Publications Ltd.

Creswell, J. W., \& Clark, V. L. P. (2011). Designing and conducting mixed methods research. Washington DC: SAGE publications.

Halliday, M. A. K., \& Hasan, R. (1986). Language, context and text: Aspects of language in a social semiotic perspective. Waurn Ponds, Vic: Deakin University Press.

Halliday, M. A. K., \& Matthiessen, C. M. I. M. (2004). An introduction to functional grammar (3rd ed.). London: Arnold.

Hoang, V. V. (2015a). The development of the ten-year English textbook series for Vietnamese schools under the National Foreign Language 2020 Project: A cross-cultural collaborative experience. VNU Journal of Science: Foreign Studies, 31(3), 1-17.

Hoang, V. V. (2015b). Teachers' evaluation of primary English textbooks for Vietnamese schools developed under the National Foreign Language 2020 Project: A preliminary internal survey. VNU Journal of Science: Education Research, 31(4), 1-15.

Hoang, V. V., Nguyen, T. C., Le, K. D., Phan, C. N., Vu, M. T., Luong, Q. T., \& Kaye, D. (2015a). Tiếng Anh 7 Sách Giáo Viên Tập 1 [English 7 Teacher's book Volume 1]. Hanoi: Vietnam Education Publishing House.

Hoang, V. V., Nguyen, T. C., Le, K. D., Phan, C. N., Vu, M. T., Luong, Q. T., \& Kaye, D. (2015b). Tiếng Anh 7 Sách Hoc Sinh Tập 2 [English 7 Student book Volume 2]. Hanoi: Vietnam Education Publishing House.

Kress, G. R., \& Van Leeuwen, T. (1996). Reading images: The grammar of visual design $\left(1^{\text {st }}\right.$ ed.). London, New York: Routledge.

Kress, G. R., \& Van Leeuwen, T. (2006). Reading images: The grammar of visual design $\left(2^{\text {nd }}\right.$ ed.). London, New York: Routledge.

Le, V. C. (2015). English language education innovation for the Vietnamese secondary school: The Project 2020. In B. Spolsky \& K. Sung (Eds.), 
Secondary school English in Asia: From policy to practice (pp. 182-200). New York: Routledge.

Martin, J. R. (1992). English text: System and structure. Philadelphia: John Benjamins Pub. Co.

Martin, J. R., \& Rose, D. (2007). Working with discourse: Meaning beyond the clause. London: Bloomsbury Publishing.

Mueller, G. A. (1980). Visual contextual cues and listening comprehension: An experiment. The Modern Language Journal, 64(3), 335-340.

Nguyen, H. T. M. (2011). Primary English language education policy in Vietnam: Insights from implementation. Current Issues in Language Planning, 12(2), 225-249.

Omaggio, A. C. (1979). Pictures and second language comprehension: Do they help? Foreign Language Annals, 12(2), 107-116.

Painter, C., Martin, J. R., \& Unsworth, L. (2013). Reading visual narratives: Image analysis of children's picture books. CT: Equinox Publishing.

Royce, T. (1998). Synergy on the page: Exploring intersemiotic complementarity in page-based multimodal text. JASFL Occasional Papers, 1(1), 25-49.

Stokes, S. (2002). Visual literacy in teaching and learning: A literature perspective. Electronic Journal for the Integration of Technology in Education, 1(1), 10-19.

Unsworth, L. (2004) Comparing school science explanations in books and computer-based formats: The role of images, image/text relations and hyperlinks. International Journal of Instructional Media, 31(3), 283-301.

Unsworth, L., \& Chan, E. (2009). Bridging multimodal literacies and national assessment programs in literacy. Australian Journal of Language and Literacy, 32(3), 245-257.

Unsworth, L., \& Ngo, T. (2014). Vai trò của hình ảnh trong sách giáo khoa day tiếng Anh ở Việt Nam: Part 1 [The role of images in English language textbooks in Vietnam: Part 1] (Vol. 11, pp. 104). Hanoi, Vietnam: Linguistics Society of Vietnam. 
Wright, A. (1989). Pictures for language learning. Cambridge \& New York: Cambridge University Press.

\section{APPENDIX}

\section{Interview Questions Sheet}

\section{Consent notice:}

Your information will be used in the project. Your personal information, however, will be kept confidential throughout the project. Thank you.

\section{SECTION A: Teacher Identity}

Name

School

Length of teaching experience

\section{SECTION B: Interview Questions}

1. How long have you taught using Tieng Anh book?

2. What is your general opinion about the format of the book?

3. Please refer to the images in the book. What do you think about the images on:

a. Getting started section page 6

b. Exercise 2 page 7

c. Vocabulary Exercise 1 page 8

d. Vocabulary Exercise 3 page 8 and 9

e. Grammar Exercise page 9

f. Grammar Exercise 1 page 10

g. Grammar Exercise 5 page 10

h. Communication Exercise page 11

i. Reading Exercise 1 page 12

j. Speaking Exercise 6 page 12

k. Listening Exercise 1 page 13

1. Writing Exercise 4 page 13

m. Vocabulary Exercise 1 page 14

n. Project Exercise 1 and 3 page 15

4. Have you ever had any challenges in using the book?

\section{Thank you for your participation.}

